\title{
Creating a Welcoming and Engaging Environment in an Entirely Online Biomedical Engineering Course
}

\author{
E. K. Bucholz (1D \\ Department of Biomedical Engineering, Duke University, Durham, NC, USA
}

(Received 30 June 2020; accepted 23 August 2020; published online 17 September 2020)

\begin{abstract}
In the spring of 2020, brick and mortar colleges had to abruptly adapt to the reality of COVID-19 and transition to entirely online environments in a manner of weeks. This required a rapid ( $<2$ weeks) acquisition of knowledge and flexibility in using technology, most commonly Zoom. Upon completion of the semester, and after debriefing with numerous faculty teaching required courses across the biomedical engineering department at Duke University, the most common comments were that the online engagement and the online environment were nothing close to the traditional classroom environment: students were less likely to show up; less likely to enable their cameras so you could see their faces; and less likely to ask or answer questions in class. To address these issues, in this paper we make easily implementable recommendations that will increase engagement and improve the inclusivity of online courses that can be applied to any biomedical engineering course offered in an online environment. Student engagement is especially important for promoting student learning as has been well documented in education research (Taylor and Parsons in Curr. Issues Educ, 2011. Retrieved from http://c ie.asu.edu/; Armstrong in The Best Schools: how human development research should inform educational practice. Association for Supervision and Curriculum Development (ASCD), Alexandria; 2006). The four recommendations for improving the engagement in the online classroom are: (1) make it a priority to stress the importance of having their cameras on during lecture and explain why it's important; (2) have a "Daily Question" at the start of lecture where all students respond in chat followed by a brief discussion; (3) make use of the polling feature in Zoom to frequently assess student understanding and upon discovering student confusion on any given question, send them to breakout rooms to discuss, incorporating a quick active learning exercise that can help reduce the monotony of online lecture; and (4) create handouts that are circulated prior to class for students to take different pieces of a particular problem, solve them in
\end{abstract}

Address correspondence to E. K. Bucholz, Department of Biomedical Engineering, Duke University, Durham, NC, USA. Electronic mail: ekb@duke.edu their teams in individual breakout rooms, and then discuss the content and results back in class with all teams together. These techniques were shown to increase engagement and attendance and fostered a welcoming environment in the online classroom, contributing positively to student experience and in turn allowing students to achieve student learning outcomes despite the difficult circumstances.

Keywords-Active learning, Inclusive environment, Student engagement.

\section{CHALLENGE STATEMENT}

In the spring of 2020, brick and mortar colleges had to abruptly adapt to the reality of COVID-19 and transition to entirely online environments in a manner of weeks. This required a rapid ( $<2$ weeks) acquisition of knowledge and flexibility in using technology, most commonly Zoom. This adjustment was fraught with technological, academic, and pedagogical challenges. Traditional brick and mortar engineering faculty are not trained nor accustomed to providing significant online content and the fast turnover rate meant faculty showed up for the first day of online teaching underprepared. After debriefing numerous faculty across the biomedical engineering department at Duke University following the conclusion of the Spring 2020 semester, most faculty noted that the online engagement and the online environment was nothing close to the traditional classroom environment: students were less likely to show up; less likely to have their cameras on so you could see their faces; and less likely to ask or answer questions in class. Faculty mentioned anecdotally that students were so disengaged that when class was over, many students failed 
to leave the Zoom classroom even $30-45 \mathrm{~min}$ after class had completed, evidence that they had left the physical room a long time ago and simply did not notice that class had finished. These are problems that faculty have never experienced in an in person class. Several classes did not have these problems and from these experiences we propose easily implementable recommendations to other faculty to improve the engagement and inclusivity of their respective biomedical engineering courses. Student engagement is especially important for promoting student learning as has been well documented in education research. ${ }^{1,6}$ We will examine one such class to understand how these techniques can be implemented and the outcomes they created.

\section{NOVEL INITIATIVE}

BME $303 \mathrm{~L}$ is taught mostly to juniors in the spring semester and had 65 students in the spring of 2020 . As with many other faculty, due to COVID-19, the course transitioned to online learning in the middle of the semester. On the first day of online class, the faculty member teaching the course, upon seeing all the blank windows with names but no faces, asked students to turn their cameras on. The system setup for the faculty member was such that she could view both the material she was screen sharing as well as the students faces. Such a setup is imperative as if faculty are not able to see their students' faces they are missing all of the visual cues they normally receive in the traditional classroom setting; without video faculty are literally flying blind and unable to adapt to their audience. Upon request, students quickly turned on their cameras and the professor reminded them every day for the first several weeks, making it an initial focus and explaining to students why it was important, until it became a habit and expectation that the students knew their camera should be on and the request did not need to be made anymore. As has been well documented when utilizing active learning techniques or flipped classroom pedagogies, explaining the rationale for a particular request goes a long way with getting student buy-in. ${ }^{5}$

After debriefing with other faculty who taught required courses in the spring of 2020 , it was clear that if over $50 \%$ of students turned their cameras off, it became a positive feedback loop where fewer and fewer students turned their cameras on, a form of peer pressure with each student not wanting to stand out. Therefore, it is imperative that faculty focus on getting as many students as possible to turn their cameras on for the duration of lecture and that expectation is set at the outset of the course (and perhaps written in the syllabus). While the faculty member does not under any circumstances recommend shaming, or calling students out for not turning on their cameras, explaining the reasoning behind wanting cameras to be on should go a long way to allay fears as well as allowing students an opportunity to communicate their privacy concerns to the instructor either privately or anonymously. It should also be mentioned that students may have limited access to the internet in their home environments and it should be the responsibility of the university to do their best to survey students' needs and provide broadband internet and/or prioritize university housing to those who are particularly at a disadvantage. In the fall, the faculty member intends to survey all the students in class prior to the start of the semester and for students who answer that they are unable to turn on their video, the faculty member plans to have the TAs monitor the Zoom site and write down the names of the students who fail to turn their video on. The faculty member then will reach out to the students to set up special Zoom office hours to check in on these students as a group to help make sure they feel part of the classroom community. The faculty member will also encourage students to post a static picture of themselves so they can at least put a face to their voices, which will help the faculty member recognize students.

Having been the unfortunate recipient of a "Zoombombing" this past spring, making sure the Zoom classroom is secure from attacks can give students additional comfort that their privacy is being protected. After the incident, the faculty member created waiting rooms and required user authentication to access the classroom, essentially only allowing students who had a university provided netID to access the course. As an added benefit, only allowing students who have university credentials to login to Zoom also makes it easier to pre-assign breakout rooms. This strategy would be problematic for faculty wishing to have lots of guest lectures, or faculty who needed to login to Zoom with multiple devices. The first day this security was implemented students also had trouble accessing the classroom, something faculty members should anticipate.

At the start of every lecture, to facilitate open dialogue with students and to work on the online classroom dynamic, the faculty member initiated a "Daily Question" and expected students to answer the question in the chat window. Examples of daily questions are shown in Table 1. Most of the questions were positive, focusing on mental wellness, and encouraged open ended answers from students. Over $33 \%$ of students typically responded and students then began to chat and encourage each other with follow ups, etc. Oftentimes birthdays were mentioned as were special 
projects students had completed that they were particularly proud of. Using chat enabled students to see everyone's responses and for more than one student to respond at a time, which is a limitation of talking in an online environment such as Zoom. Often the faculty member would have a short $(<2 \mathrm{~min})$ conversation asking students follow up questions about their statements and that significantly improved the dialogue between students and the faculty member. Once the daily question was implemented, over $85 \%$ of the students who attended left their video cameras on and felt comfortable being seen by their peers and professor. In addition, after the daily question was implemented more students asked questions and felt comfortable volunteering answers than prior to implementation. While the emphasis in the spring was on mental health and overall well being given the stress of COVID-19, it is anticipated that this technique could be employed not just to build community and open communication in an online environment, but also to encourage students to reflect on their learning at the outset of class with more learning and course specific focused questions, examples of which have been provided in the table but are italicized as they were not implemented in the spring.

Other techniques initiated in the online classroom were polls that asked multiple choice questions about the material being covered using the Zoom poll tool. While in a normal environment, the faculty member would have used iClicker, in the online environment it was better to use the built in Zoom tool as it reduced the number of applications both the faculty and students had to interface with, thus reducing complexity. To set this up, the faculty member prepopulated questions in the Zoom poll prior to every class, which required visiting the Zoom room prior to the start of the online lecture. While the responses could not be recorded for the students or attributed to any particular student, the faculty member could determine how many students were participating (generally $>95 \%$ of attendees) and it was a good way to ascertain if everyone was following along with the content. If a large percentage of the students were incorrect in answering the question, the faculty member would send the students to breakout rooms where they were tasked with convincing their peers they knew the correct answer. They were then brought back into the main room and the poll was offered again to see how many minds were changed. This allowed students to make a guess, receive immediate feedback from their peers, and then find the correct answer. Most of the time, students were able to arrive at the correct answer after the breakout rooms, but occasionally more discussion would be needed to explain the correct answer to all students. This method can be implemented in any biomedical engineering course to determine how well students are grasping the content and it is an easy, low stakes way to encourage students to interact with the material and each other, deepening their knowledge of the course content.

The faculty member also made frequent use of the breakout rooms. Ahead of time, the faculty member would prepare a.pdf (included in supplemental materials) that she would then email to students and post on the course Piazza site. In the handout, there were typically assignments for the students to complete in their respective breakout rooms. For example, one breakout room team would need to simulate the relaxation curve with a set of constants, while another breakout room team would simulate the same relaxation curve with a different set of constants. Students then were asked to draw their resultant graphs on the.pdf using the annotate function in the Zoom tool and describe them to the class. This was then discussed with the whole class and students were then given another set of constants to simulate another condition and sent back to their breakout rooms. In this way, the students were kept engaged and active most of the time during lecture, much like they were in the traditional classroom.

\section{REFLECTION}

Active learning and creating an inclusive and welcoming environment have long been known to be important contributors to students achieving the learning outcomes specified by the course. ${ }^{3,2}$ Students that feel valued and appreciated in class work harder and feel more connection to the material and are more motivated to learn. ${ }^{4}$ These personal connections to other students in the class and the faculty member teaching it are possibly the most valuable piece of the learning experience as learning is not unidirectional or solely communication of content, but rather a process that is give and take; that encourages interaction and exploration of the content with their peers and the faculty member as it encourages students to work higher up the Blooms taxonomy pyramid. With many courses by necessity starting online in the fall, creating a welcoming environment that is $100 \%$ online for the duration of the semester will be all the more challenging since there will be no face to face time as was the case in the spring semester. After reflecting on the good and the bad of the spring 2020 semester, there are many ways we can improve the experience for the students to do a better job of teaching them in the new reality we currently find ourselves in.

Prior to the start of the online class session, much time was devoted to thinking about ways for students 
TABLE 1. Daily question examples.

Examples of daily questions

What is one thing you haven't missed as much as you thought you would?

What is the best thing you did yesterday?

What are you most excited about today?

What was the most surprising thing that happened yesterday?

What is your favorite time/activity of the day?

What do you appreciate now that you didn't appreciate as much prior to COVID-19?

What would be your most useful advice for other students on the homework due in several days?

What have you found most interesting about Fourier Transforms (e.g. fill in topic here)?

How do you think the topics we are covering in class will affect your choice of occupation (it's okay to be honest)?

Why do you think, we make you learn about convolutions (e.g. fill in topic here)?

to actively engage with the course in the new virtual environment. By implementing these recommendations, the faculty member had very high attendance for the course ( $>80 \%$ or more than 52 out of 65 enrolled students came to class every session). In addition, around $90 \%$ of the attendees or around 45 of the 52 students who attended class had their video on. For the polls, the professor got over $95 \%$ of the students participating as could be determined by the number of answers received in the Zoom poll software. With the daily question, usually only $30 \%$ of the students responded with their answers before students began to comment on one another's responses and people stopped answering the question and instead asking follow up questions or congratulating others. Even though not everyone wrote a response, it was an olive branch that made students feel more relaxed and comfortable in the classroom environment and is an easy daily activity that can open students up to learning and make them more likely to ask and answer questions, fostering a positive work environment for the students. While in the spring the faculty member was focused on the overall well-being of the students, in the fall, with students more adjusted to the new normal, instructors could consider asking a BME specific course question that encourages reflection and dialogue about the course content and examples of questions that might be used are included in italics in Table 1.

There are several things that could be improved or streamlined for the following semester. First, the faculty member spent significant time preparing Zoom polls for the course which involved going to the Zoom room that was to be used and prepopulating it with the polls for the day. Later the faculty member realized she could simply have one default poll with answers A, B, $\mathrm{C}, \mathrm{D}$, and $\mathrm{E}$ and then give the question and answer in either PowerPoint or write it on the doc cam or handout she had provided to the students in electronic form. This would also allow the faculty to adapt on the fly and ask questions she hadn't planned to ask, as she sometimes does in in person class. This would strike a nice balance and would reduce the preparation required for each online class.

For larger classes, the breakout rooms used should be assigned prior to the start of class. For the first several weeks of online class, the faculty member randomly assigned them every time in class to streamline the process and in a large online class $(65$ students) that was not as successful as having more regular groupings of students. With such a large class, students would interact with one student and by random probability never interact in a breakout room with that student again. For classes less than 20, assigning breakout rooms randomly could be beneficial as all students would get a chance to interact with one another and would help foster a sense of community, which is developed through frequent interactions. For students to have a positive breakout room experience, they do need to develop familiarity with one another and so encouraging ice breakers at the start, particularly in an entirely online course would be beneficial. Towards the end of the spring semester, the faculty made breakout rooms in Zoom ahead of time that were the same for the last 3 lectures. The students commented that this was a positive change and resulted in better collaboration in the breakout rooms.

In the fall version of the online class, which is anticipated to be 50 or more students, the faculty member expects to have students pick seats and assign groups at the beginning of the semester based on the seating arrangements which is how it would function in a normal classroom environment. The faculty member is going to ask students to come up with a team name relating to the course content in the fall and then name the breakout rooms for the rest of the semester. In this way the faculty will be able to call on students of one cohort but naming the teams will make them more memorable for both students and faculty. While there is benefit to having students mix, ultimately students 
felt less comfortable opening up to people they didn't know and their work product was affected when they were in random groups of students they were unfamiliar with. In smaller classes, random assignment might work but in larger classes it was possible that students only work one time with a given student, which is not long enough for them to form a relationship or develop trust. During the first part of the spring 2020 online experiment, assigning breakout room teams was not possible using the Zoom tool through Sakai but given recent developments that is likely to have changed. There were also some technical challenges with the TA assisting in the breakout rooms. Making the TA host instead of co-host would allow the TA to help assign/adjust breakout rooms instead of the faculty member who was busy fielding questions from the in class exercise and conducting lecture.

Another improvement that would help is instead of sending.pdfs to the students, the faculty member in the fall plans to send a google slides link during class for two example activities that have been proposed. In the first activity, students would access the table and complete their problem with their teammates at the same time as everyone is filling in the table. After the breakout rooms, the whole class would look at the answers and see if they agree with their classmates. In the 2nd proposed activity, in their breakout rooms, students would scroll to their team slide and plot the solution of the discrete convolution requested. Students would edit their respective google slide for their breakout room and answer any questions and then when the teams are brought back into the main Zoom classroom, the faculty member can quickly scroll through the plots and responses for the different problems and students can explain their reasoning. In addition, all students would have access to these google slides for studying purposes. Students often mention they want more practice problems and given that each breakout room would have a slightly different problem, this would provide additional materials that were curated by other students and verified in class.

The feedback the faculty member received for the spring 2020 was very positive. Students commonly mentioned the welcoming, friendly environment and one student mentioned coming to class felt like coming to a "family gathering." Students by and large appreciated the synchronous content both for how it made the days more routine and because it was good to see other people as it made the class feel more like a normal class. When asked to use one word to describe the overall course the most popular answer was interesting ${ }^{4}$ followed by rewarding, ${ }^{5}$ challenging, ${ }^{5}$ difficult, ${ }^{5}$ enlightening, ${ }^{5}$ and fun $^{5}$ to name a few of the most common answers given.

Making the changes recommended in this paper in an online class will significantly enhance the classroom dynamic in the fall semester which in turn will allow students to achieve the learning outcomes of the course by creating a positive work environment where students are open and receptive to learning which has been well documented to increase student performance and retention of material.

\section{ELECTRONIC SUPPLEMENTARY MATERIAL}

The online version of this article (https://doi.org/10. 1007/s43683-020-00024-x) contains supplementary material, which is available to authorized users.

\section{REFERENCES}

${ }^{1}$ Armstrong T. The Best Schools: how human development research should inform educational practice. Alexandria: Association for Supervision and Curriculum Development (ASCD); 2006.

${ }^{2}$ Bryson $\mathrm{C}$, Hand $\mathrm{L}$. The role of engagement in inspiring teaching and learning. Innovations in Education and Teaching International. 2007;44(4):349-62. https://doi.org/ $10.1080 / 14703290701602748$.

${ }^{3}$ Collaco C. Increasing student engagement in higher education. Journal of Higher Education Theory and Practice. 2017;17(4):40-7.

${ }^{4}$ Lumpkin A, Achen RM, Dodd RK. Student perceptions of active learning. College Student Journal. 2015;49(1):121-33.

${ }^{5}$ Talbert R. Flipped Learning: A guide for higher education faculty. Sterling: Stylus Publishing; 2017.

${ }^{6}$ Taylor L, Parsons J. Improving student engagement. Curr Issues Educ. 2011. Retrieved from https://cie.asu.edu/.

Publisher's Note Springer Nature remains neutral with regard to jurisdictional claims in published maps and institutional affiliations. 